\title{
EL CANDOMBE ARGENTINO COMO REPERTORIO DE ACCIÓN CULTURAL POPULAR
}

Jorge Iván Jaramillo Hincapié *

DOI: https://doi.org/10.33571/revistaluciernaga.v11n21a6

\begin{abstract}
A la memoria de Mari Mariño (mayo del 2010)
"...los afroargentinos, no pasaron por la esclavitud en apática dependencia, ni con entusiasmo despreocupado, ni con triste nostalgia por la libertad en el más allá, sino desarrollando un universo que seguía siendo fundamentalmente africano, a pesar de ser expresado en formas occidentales" Picotti (1998, pág. 29).
\end{abstract}

\begin{abstract}
Resumen
En el artículo se describe el repertorio de acciones populares que desde lo subalterno girando hacia acciones de resistencia, se realizan en torno al candombe en Argentina; manifestación cultural de origen negroafricano, que aunque es considerado Patrimonio Cultural de la Humanidad, se esfuerza por su visibilización en el hegemónico discurso cultural de ese país. El análisis del trabajo de campo se realizó con la Asociación Civil África Vive, la Sociedad de Socorros Mutuos Unión Caboverdeana de Dock Sud y el Proyecto de Apoyo a los Afroargentinos y sus Organizaciones de Base.
\end{abstract}

Palabras clave: afroargentinos; candombe; culturas populares; repertorios de acción.

Recibido. Marzo 11, $2019 \quad$ Aceptado. Abril 01, 2019

* Doctor en Conocimiento y Cultura en América Latina (IPECAL - México), Posdoctor en Comunicación, Educación y Cultura (Universidad Nacional de Córdoba (Argentina) y Universidad Santo Tomás (Colombia). Doctorando en Antropología Social (IDAES -UNSAM, Argentina). Magíster en Ciencias Sociales (Universidad Nacional de General Sarmiento - Argentina). Especialista en Docencia Universitaria (Universidad Complutense de Madrid - España). Comunicador Social - Periodista (Universidad de Antioquia - Colombia). Profesor Honorario Universidad Nacional Daniel Alcides Carrión - Perú. Profesor Asociado, Universidad Central - Departamento de Comunicación Social y Periodismo. Orcid. https://orcid.org/0000-0001-7977-396X ; e-mail. ivanjaramillo458@gmail.com 


\section{ARGENTINEAN CANDOMBE AS A REPERTOIRE OF POPULAR CULTURAL ACTION}

Jorge Iván Jaramillo Hincapié *

DOI: https://doi.org/10.33571/revistaluciernaga.v11n21a6

To the memory of Mari Mariño (May 2010)

"...the Afro-Argentines did not go through slavery in apathetic dependence, neither with unconcerned enthusiasm, nor with sad yearning for freedom in the hereafter, but by developing a universe that remained fundamentally African, despite being expressed in occidental shapes" Picotti (1998, p. 29).

\section{Summary}

The article enquires about candombe in Argentina, a cultural manifestation of black African origin, that even it is considered Cultural Heritage of Humanity, it strives for its visibility in the hegemonic cultural discourse of this country. The analysis of the fieldwork was carried out in compliance with the Civil Association Africa Vive, Sociedad de Socorros Mutuos "Unión Caboverdeana" of Dock Sud and the Project to Support Afro-Argentineans and their Grassroots Organizations.

Key words: afro-argentineans; candombe; popular cultures; action repertoire.

Recibido. March 11, $2019 \quad$ Aceptado. April 01, 2019

* Doctor en Conocimiento y Cultura en América Latina (IPECAL - México), Posdoctor en Comunicación, Educación y Cultura (Universidad Nacional de Córdoba (Argentina) y Universidad Santo Tomás (Colombia). Doctorando en Antropología Social (IDAES -UNSAM, Argentina). Magíster en Ciencias Sociales (Universidad Nacional de General Sarmiento - Argentina). Especialista en Docencia Universitaria (Universidad Complutense de Madrid - España). Comunicador Social - Periodista (Universidad de Antioquia - Colombia). Profesor Honorario Universidad Nacional Daniel Alcides Carrión - Perú. Profesor Asociado, Universidad Central - Departamento de Comunicación Social y Periodismo. Orcid. https://orcid.org/0000-0001-7977-396X ; e-mail. ivanjaramillo458@gmail.com 


\title{
O CANDOMBE ARGENTINO COMO REPERTÓRIO DE AÇÃO CULTURAL POPULAR
}

Jorge Iván Jaramillo Hincapié *

DOI: https://doi.org/10.33571/revistaluciernaga.v11n21a6

Em memória de Mari Mari Mariño (maio de 2010)

"os afro-argentinos não passaram pela escravidão na dependência apática, nem com entusiasmo despreocupado, nem com triste nostalgia da liberdade no futuro, mas desenvolvendo um universo que permaneceu fundamentalmente africano, apesar de expresso em formas ocidentais" Picotti (1998, p. 29).

\begin{abstract}
Resumo
O artigo investiga o candombe na Argentina, uma manifestação cultural de origem negra africana, que embora seja considerada Patrimônio Cultural da Humanidade, busca sua visibilidade no discurso cultural hegemônico deste país. A análise do trabalho de campo foi realizada com a Associação Civil África Vive, a Sociedade de Socorros Mútuos Unión Caboverdeana de Dock Sud e o Projeto de Apoio aos Afro-Argentinos e suas Organizações de Base.
\end{abstract}

Palavras-chave: afro-argentinas; candombe; culturas populares; repertórios de ação.

Recebido. Março 11, 2019

Aceitado. Abril 01, 2019

* Doctor en Conocimiento y Cultura en América Latina (IPECAL - México), Posdoctor en Comunicación, Educación y Cultura (Universidad Nacional de Córdoba (Argentina) y Universidad Santo Tomás (Colombia). Doctorando en Antropología Social (IDAES -UNSAM, Argentina). Magíster en Ciencias Sociales (Universidad Nacional de General Sarmiento - Argentina). Especialista en Docencia Universitaria (Universidad Complutense de Madrid - España). Comunicador Social - Periodista (Universidad de Antioquia - Colombia). Profesor Honorario Universidad Nacional Daniel Alcides Carrión - Perú. Profesor Asociado, Universidad Central - Departamento de Comunicación Social y Periodismo. Orcid. https://orcid.org/0000-0001-7977-396X ; e-mail. ivanjaramillo458@gmail.com 


\section{Introducción}

En el artículo se indaga por el candombe en Argentina, manifestación cultural de origen negroafricano, que tiene presencia en la cultura Uruguaya desde hace más de doscientos años, y es considerado Patrimonio Cultural de la Humanidad. De lado se deja la discusión de sí el candombe es uruguayo o argentino [1] en tanto este es un debate zanjado, reconociendo la presencia de diferentes rasgos [2] comunes en la expresiones culturales del contingente negro en Latinoamérica. Tampoco se aborda el análisis de las letras del candombe. Nos adentramos al candombe en Argentina mediante entrevistas y observaciones realizadas a integrantes de la Asociación Civil África Vive, la Sociedad de Socorros Mutuos Unión Caboverdeana de Dock Sud y el Proyecto de Apoyo a los Afroargentinos y sus Organizaciones de Base, en las que tienen presencia integrantes de la familia Lamadrid, quienes han abierto un espacio al candombe dentro de las artes del Gran Buenos Aires.

\section{Encuentros con la Familia Lamadrid}

María Magdalena Lamadrid "Pocha" de la organización África Vive, comenta que los encuentros, son un espacio para que personas de distintos orígenes conozcan no solo a la agrupación sino a las "tías", depositarias de una tradición oral que viene desde comienzo del siglo $X X$. También se conocen las nuevas generaciones, se integra la familia Lamadrid con los invitados y se visibiliza la organización.

La Familia, es el nombre que le dan a la agrupación de candombe que a su vez está integrada por miembros de la misma familia Lamadrid. A sus encuentros se vinculan amigos/as, académicos/as y miembros de otras organizaciones así como público que:

"se va enterando que el candombe argentino existe y está vivo, aunque no esté dentro de los programas de la Provincia o el Gobierno de la Ciudad de Buenos Aires".
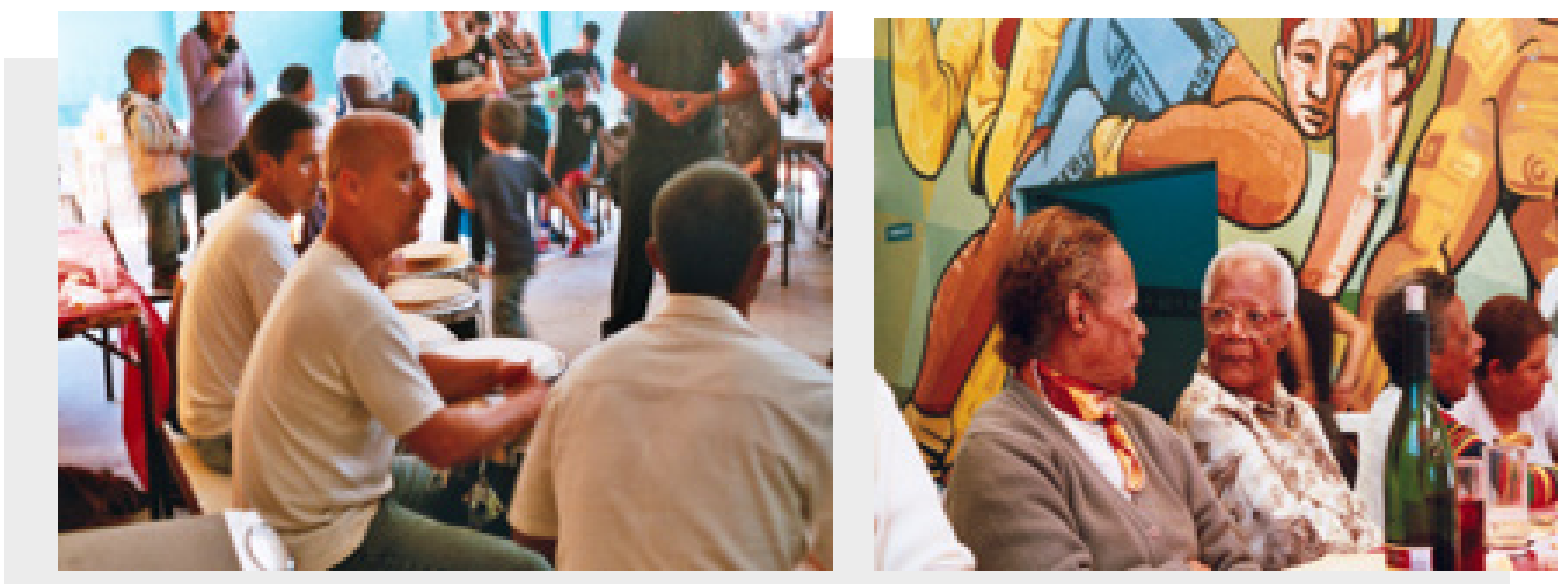

Imagen: Iván Jaramillo, La Matanza. 
A los encuentros [3] también asisten periodistas, fotógrafos, académicos, dirigentes y miembros de otras organizaciones afroargentinas, estudiantes y vecinos del Partido de la Matanza. Las jornadas se inician con el típico asado argentino, vino y la presencia de dos de las "tías mayores" de la familia.

María Magdalena indica que convoca a la comunidad negra de la siguiente manera:

"yo voy por la calle o estoy en algún bar u hospital y veo los rasgos de una persona, me le acercó y le pregunto por su nombre y apellido, ahí ya comenzamos a hablar, seguimos en contacto y algunas veces me he encontrado con gente que iba a la Casa Suiza o incluso familiares lejanos o familias amigas de otros momentos".

Magdalena, empezó a concientizar acerca del ser negro en Argentina, mediante charlas en la casa de uno de sus hermanos, su idea era aportar a la reconstrucción de la identidad, la autoidentificación. Según ella esto ha dado frutos y hoy día sus primos Hugo Lamadrid y Carmen Yanone "Pelusa" y su hija Mailén Lamadrid están trabajando directamente en la organización:

"Yo inicié esto en las casas de mi familia, de mis primas, contándole a los chicos que tenían ya su orquestita, su conjuntito. Yo les venía diciendo de que ellos tenían que apoyarse en el candombe argentino, porque ellos no lo tuvieron que ir a aprender a ningún lado, que estaba en la familia, que si ellos saben tocar los tambores es porque estaba en la familia, creo que eso los hizo más vagos, porque como lo tuvieron ahí, no le dieron el valor que tenía, entonces estuve casi dos años dando esa charla, casa por casa, familia por familia.

Yo tengo una sobrina que crie desde los 9 meses, se llama Celeste, y un día, llegó de trabajar a la tarde y me la encuentro en la escalera llorando que el papá y la mamá no la dejaban ir a un baile en el barrio, era en un club que hay en el barrio. Entonces le digo: déjame descansar un rato te llevo yo; que conmigo la dejaban ir. Cuando llegamos ahí me encuentro con que estaba el conjunto de mi hermano y abren el show tocando el candombe argentino, yo lloraba, porque a mí esas cosas me ablandan en el sentido de que dos años tuve que luchar para que todos entendieran que esto es lo que tienen adentro. No es una cosa que lo tienen que aprender".

(Entrevista a María Magdalena , Buenos Aires. 15 de mayo del 2009)

\section{1"Yo Desperté"}

[María Magdalena] "Yo bailé desde chica, yo no sé cuando desperté creo que fue cuando tenía 12 años, hasta ese momento yo iba a la Suiza a mirar, un día me dijeron bailá y salí y no sé qué bailé, pero la cuestión es que al rato vino un hombre que me dijo "vas a tener que aprender tres coreografías, nos vamos dentro de cuatro días" y bueno, me las aprendí. Oswaldo se llamaba el petizo, y le gustaba escuchar el tambor y practicar, porque era un tipo que te hacía practicar dos horas 
todos los días de lunes a viernes. Ensayamos en los lugares más raros; la mamá de él limpiaba una sinagoga, y se la prestaban a él a la noche para que fuéramos a ensayar ahí. Y ahí aprendí a mover las manos, a mover la cintura, o sea encontré el estilo y yo me di cuenta de que los chicos, o sea mi familia, les faltaba eso, les faltaba saber de que esto del baile es una cosa de que no hay muchos que lo hagan.

(Entrevista a María Magdalena , Buenos Aires. 15 de mayo del 2009)

El "desperté" designado en el discurso de nuestra entrevistada se podría analizar en clave de despertar étnico y racial, en un clima generado en todo el continente desde los años setenta con el surgimiento de los movimientos negros en Estados Unidos, y en la década del ochenta en toda Latinoamérica con la eclosión de movimientos sociales indigenistas que fueron adhiriendo a su causa la problemática afro-latinoamericana, hasta la década de los noventa donde en varios países se contempla en las constituciones nacionales la inclusión de las comunidades negras y muchas de ellas asumen movimientos propios e independientes.

Para María Magdalena el candombe argentino existió, existe y ella es exponente directa del mismo, por eso dice: "es lo que tenemos adentro" (en el discurso de nuestra entrevistada el término candombe está relacionado con la nación, en todas sus interpelaciones, como un común diferenciador frente a la permanente oposición (discursiva) a la práctica del candombe uruguayo en algunos sectores de la ciudad).

[María Magdalena] Cuando yo bailo, yo no bailo para el público, yo bailo para mí. Entonces yo les decía a mis sobrinos siempre que agarren los tambores piensen y métanse en el sonido que quieren sacarle a ese tambor. Y bueno hasta ahora, vos ves tocar a mi sobrino Cutín y agacha la cabeza y toca para él. Y mi hermano lloraba de verlo tocar, por ser tan tímido, tan calladito que no se puede creer que toque tan bien, que sepa el ritmo y que lo toque bien. $Y$ eso es lo que me gustó y todos dicen que es mi preferido y es verdad, no nos llevamos bien porque él es muy impuntual; pero es derecho. Ellos saben cómo bailo y saben acompañarme, ¿por qué no mostrar esto al mundo?

(Entrevista a María Magdalena , Buenos Aires. 15 de mayo del 2009)

Ella nombra lo innombrable, lo resignifica, le atribuye un nuevo valor y lo trae a la escena actual desde su propia interpelación, ella muestra lo que estaba subsumido o soterrado por el efecto de la hegemonía en el campo cultural. Tal vez no se podría hablar del mismo candombe de finales del siglo XIX, pero si de un arte reconfigurado o resignificado, todo a partir de los recuerdos y contenidos que aún quedan en la memoria de las y los descendientes de las familias negras en la Argentina. 


\subsection{La Suiza}

[Paulina] "Nosotros los caboverdianos (esta identificación se refiera a los descendientes de los inmigrantes venidos de las islas de Cabo Verde a comienzos del siglo XX) íbamos a la Suiza, pero siempre daba la sensación de estar los unos a un lado y los otro de otro. Conocíamos a todas las familias y la pasábamos muy bien en los bailes, pero no nos terminábamos de juntar del todo" (Paulina, Dock Sud, agosto del 2009).

La mención que se hace a la Suiza, refiere a la casa en la que se realizaban los bailes de carnaval convocados por el Shimmy Club desde 1920 hasta 1970. Los Lamadrid era una de las familias asiduas a esos eventos. En general los entrevistados hacen mención a los bailes en la Casa Suiza, en la que cada mes, "así fuera pagando, se encontraba toda la Raza".

"Siempre íbamos con toda mi familia a la Suiza, desde los más chiquitos hasta los grandes, conocíamos a todas las familias y siempre allí nos enterábamos cómo andaban muchas de nuestras amistades y era un momento de fraternidad muy intenso"

(Marí Mariño, San Telmo, febrero del 2010)

"Yo estaba muy chica y la que me llevaba era mi abuela, lo que más me gustaba era que cuando dejaban desocupada la pista yo me ponía a patinar con mis amiguitas, pero allí estábamos todas las familias y era un momento de encuentro de todos"

(Beba Datarmani, San Telmo, febrero del 2010)

"Yo allí iba a bailar, a encontrarme con mis amistades, tocaba el tambor y era el momento para ver a muchas personas que no veíamos durante el mes"

(Hugo Lamadrid, noviembre del 2009)

\section{El candombe}

"El candombe como modo de ser de nuestra cultura ha tenido origen en distintos lugares del continente americano y aún tiene vigencia. La Argentina no es la excepción. El candombe en la República Argentina encuentra sus orígenes en la era colonial y desde ese momento ha tenido un desarrollo ininterrumpido hasta nuestros días. Como hecho social, cultural y musical, el candombe fue mantenido por nuestros ancestros en el seno de nuestras familias quienes supieron sostenerlo y trasmitirlo a las generaciones jóvenes con orgullo y profunda espiritualidad".

(Entrevista a María Magdalena , Buenos Aires. 15 de mayo del 2009) 
El candombe como música internacional, surge desde un panorama local con un repertorio local [4]. Siguiendo el argumento de Paul Gilroy en el Atlántico Negro, por la transnacionalización de la industria cultural se cruzan signos racializados nacionales en la diáspora africana; una consecuencia no esperada de la industria cultural; apuntamos a este proceso de transnacionalización por el cual aparece la rumba afro-cubana entre los afrodescendientes de la ciudad de Buenos Aires desde al menos mediados del siglo XX.

"Los candombes que pasaron de boca en boca los recuperamos acordándonos de lo que cantábamos cuando éramos chicos, las letras que les escuchábamos a nuestras viejas y que nos iban enseñando. Por ejemplo, mis tías, que son las mellizas cantaban entre ellas los candombes, se retrucaban. Esas letras nos las aprendimos nosotras y hablo de lo que yo sé y María Elena; que es lo que tocan en Bakongo.

(Entrevista a María Magdalena , Buenos Aires. 15 de mayo del 2009).

La mención de nuestra entrevistada sobre el grupo Bakongo [5] da a lugar a indicar que en varias ocasiones nos aproximamos a esta organización donde tuvimos la oportunidad de asistir a un evento social por su aniversario, allí logramos observar como al llegar la media noche se instalan los tambores en medio del salón y se inicia lo que denominan como música candombe. Ruth Silva (76 años), invitada especiales y miembro honorario de la Organización, al sonar los tambores, se pone de pie, se lleva una mano a su frente y otra en la cintura y empieza a danzar, todos la rodean y se inicia el baile.

En África Vive la cuestión culturalista nace como una de las primeras iniciativas para visibilizarse, inician las reuniones y todo el proyecto queda a mitad de camino por diferentes circunstancias pero Misibamba retoma esta iniciativa y la lleva a cabo. Los cantos, las letras y todo el repertorio cultural del candombe ha sobrevivido [6].

"Cuando mis sobrinos empezaron con La Familia Rumba Nuestra, tocaban de todo hasta que yo hice el trabajo casa por casa para que incluyeran esos candombes que yo me acordaba. Yo volví a mis raíces, volví al candombe".

(Entrevista a María Magdalena , Buenos Aires. 15 de mayo del 2009).

Entre el 2009 y 2010, asistimos a dos presentaciones públicas de su agrupación de candombe, una en el Centro Cultural Ricardo Rojas y otra en El Rosedal. Esto nos sirve para tener en cuenta que hay otras agrupaciones recuperando el candombe argentino. Carmen Yanone "Pelusa", quien práctica y permanentemente se presenta en diferentes escenarios públicos del país, advierte del significado del candombe para la cultura negra argentina.

[Carmen Yanone] "Yo puedo decir que soy afroargentina, este movimiento me parece muy maravilloso, necesitamos que todo el pueblo argentino se conscientice de que todos los afroargentinos y todos los afro que están llegando tienen que ver con este bendito país, nosotros somos quinta generación que durante muchísimos años, hemos mostrado nuestra cultura a través del candombe argentino. Tal vez son muy pocos los que saben que nosotros los argentinos tenemos una música milenaria que es el candombe argentino. El movimiento se está mostrando a través de su cultura, el baile y el canto de esta música nuestra".

(Entrevista, Carmen Yanone, Buenos Aires, septiembre de 2009). 
Carmen Yanone asume la raíz afro como algo referido directamente en un sentido étnico, lo afro como equivalente a lo negro desde su propia acepción, y un sentido abarcativo al mencionar "todos los afroargentinos y todos los afros que están llegando", es una identidad ampliada hacia una concepción de diáspora que engloba no sólo a los afroargentinos sino a todas las organizaciones y el movimiento migratorio como el que se viene dando los últimos años en la argentina.

En entrevista con Juán Suaqué, presidente de la Asociación Cultural Misibamba, le preguntábamos por la posibilidad de trabajar en conjunto con las otras organizaciones afroargentinas, para el rescate de sus artes y la consolidación organizacional, comentó:

"Nosotros nos designamos como afroargentinos del tronco colonial, actualmente estamos trabajando al interior de la organización y el no juntarnos es reconocer de cierta manera que todo el contingente negro no es lo mismo, por eso la división". Con respecto a esta respuesta surge la pregunta de si en Argentina, hay una cierta etnización de las organizaciones afro. Quizás piensan que para ser un buen negro argentino es necesario ser un buen candombero [7].

Queda claro entre África Vive y Misibamba, están conformadas por afroargentinos, no tienen, en el momento "comunicación oficial" entre ellas. María Magdalena Lamadrid no se reconoce como perteneciente a la categoría usada por Misibamba de afrodescendientes argentinos del tronco colonial, incluso su mismo uso no le hace sentido, porque según ella le parece que es una expresión (categoría) exclusiva que no tiene en cuenta a otras organizaciones afroargentinas.

María Magdalena Lamadrid se define como "negra argentina descendiente de quinta generación". Estas organizaciones no realizan actividades sociales en común, y tampoco tienen comunicación, a pesar de que en ambas hay integrantes que son familiares entre si. Misibamba se ha dedicado a realizar una serie de actividades y presentaciones en conjunto con la Casa Indoafroamericana de Santa Fe liderada por Lucía Molina, haciendo jornadas de candombe y charlas en Córdoba. Recientemente participaron en la celebración del Bicentenario argentino.

África Vive se está reestructurando internamente y no posee agenda pública. En este contexto, no hay competencia alguna por representatividad de alguna de las dos organizaciones en el espacio público. Africa Vive ha optado por mantener un bajo perfil, mientras Misibamba mantiene una agenda activa.

\section{Reflexión final}

El candombe en Argentina, intentan interpelar a una escala mayor al Estado y no deja de evidenciar la importancia de nombrarle como tal. Esto quizás se explique debido a que a finales del siglo XIX e inicios del XX - como se lee en los diarios de la época [8], y argumenta George Reid Andrews- la presencia negra en el Gran Buenos Aires ha sido desvanecida hasta llegar a su completa negación [9].

Graciela Rodríguez (2008) plantea que las manifestaciones culturales implican reconquistar lo anónimo a través de dejar marcas en el sistema $y$, consecuentemente, la salida hacia los espacios libres (Pág.331). Lamborghini y Frigerio (2010) advierten que en Argentina no se puede hablar de un movimiento social como tal sino de un 
"incipiente pero dinámico movimiento social afrodescendiente". En términos de Bhabha podríamos estar hablando de ese "intersticio" del que hacen uso las organizaciones negras para instrumentalizar algunas tácticas de resistencia (en el caso que nos convoca, el candombe como repertorio de acción cultural) en el intento de instalar sus demandas en la esfera pública.

En Argentina para el siglo XX el arte de los negros fue relegado al interior de los hogares de los afroargentinos, o desplazado a la Provincia de Buenos Aires, en esos espacios cerrados íntimos se conservó y pasó de generación en generación. Por otra parte, como sugiere la tesis de Alicia Martín (2008), también fue transformado entre familias y vecindarios multirraciales de ciertos barrios de la ciudad de Buenos Aires en lo que hoy se conoce como murga porteña, una forma viva del carnaval de esta ciudad en esferas públicas locales a lo largo del siglo XX.

Si se asumen las expresiones populares como el registro de actividades que provienen desde lo subalterno [10], desde abajo, así como a manifestaciones que no están empotradas en lugares hegemónicos y que dan lectura de lugares de resistencia, se puede colegir que el candombe se inscribe (por el momento) como expresión cultural popular sin llegar a ser masivo popular, como ocurre con la cumbia argentina, el chamamé, cuarteto, rock nacional, zamba, tango o milonga.

Siguiendo a Alabarces en su libro Resistencias y Mediaciones, Estudios Sobre Cultura Popular (2008), preguntarnos hoy por lo popular exige una nueva lectura, un análisis radical que interrogue con dureza la nueva economía de lo simbólico heredada de las dictaduras y el neoconservadurismo[11]. ¿Qué ofende el presunto progresismo? ¿qué es tolerable de la aguda desigualdad simbólica?. Desigualdades harto complejas porque no solo designa -cómo se ha hecho- el acceso a determinados bienes culturales, sino también las condiciones de producción de todo lo simbólico. Además el derecho a la voz. De un modo no menos importante designa el derecho a la visibilidad y a los modos de administrarla. Lo popular nombra en la América Latina contemporánea, aquello que esta fuera de lo visible, de lo decible y de lo enunciable (Pág.25).

Alabarces (2008) deja ver su cercanía con el paradigma de los Estudios Subalternos[12] de la India, donde a partir de la lectura que hicieron todos sus integrantes de Gramsci, a la cabeza del historiador Ranahit Guha (1997/2002) se dan a la tarea de recuperar la voz de los que no tienen voz, todo a partir de una lectura a contrapelo de la historia, ya más adelante se da el debate con la pregunta de Gayatrik Spivak (1999): ¿Realmente puede hablar el subalterno?

La hegemonía silencia el entramado social subalterno; la primera alcanza a los segundos, quienes se acomodan históricamente a esa invisibilización, y hacen suyos valores de blanquitud y estrategias de enblanquecimiento.

En el paradigma de lo popular como lo expresa Michel de Certeau (1996) "...el espacio instituido por otros, caracteriza la actividad, sutil, tenaz, resistente, de grupos que, por no tener uno propio, deben arreglárselas en una red de fuerzas y de representaciones establecidas. Hace falta "valerse de". En estas estratagemas de combatientes, hay un arte de las buenas pasadas, un placer de eludir las reglas de un espacio limitante...mil maneras de hacer/deshacer el juego del otro" (Pág. 22). 
Es de advertir que las organizaciones afroargentinas están en procura de su visibilización, esto a partir de la década de 1990, cuando interpelan por un lugar en la esfera pública, en diferentes estamentos y en la sociedad en general. Dichas comunidades tratan de revertir los estigma de "negro", "cabecita negra", y todo lo relacionado con el contingente negro que poseía una carga negativa y peyorativa. Ahora lo convierten en una de sus fortalezas [13].

En las diferentes entrevistas con María Magdalena Lamadrid siempre tarareó y deletreó candombes en castellano e hizo mención de cómo en su momento también bailaron la denominada rumba abierta, salsa, etc.

Luego del anterior recorrido y las observaciones que llevamos adelante en nuestra investigación, nos surgen estas preguntas: ¿para ser un buen negro argentino hay que ser un candombero? ¿para obtener derechos de afro-reparación es necesario andar tocando candombe y convertirlo en su arte más representativo?

Es nuestro interés consignar que en este tipo de estudios, la cercanía, la empatía y también en muchas ocasiones el alejamiento permiten observaciones más concretas y críticas de la cultura popular (Bhabha, 20017), en este caso los afroargentinos dentro de una práctica cultural como lo es el candombe a la que estos actores presentan como representativa de sí mismos y bregan porque así sea en los espacios públicos a los que logran acceder, donde se siguen repitiendo ciertas prácticas hegemónicas, pero que se espera en un futuro ese visibilizarse culturalista sea la punta de lanza para la formación de cuadros políticos y de infraestructura organizativa que les permita construir una plataforma política como tal.

En la línea de Albarces y Añón (2008), se debe seguir explorando:

"...una definición de lo popular entendido como subalterno. Una definición que enfatice el plural pero que no se tranquilice en él; que incluya siempre el conflicto, el poder, la desigualdad, sin naturalizarlos ni cristalizar a los sujetos en ellos; que incorpore a la noción de popular las múltiples articulaciones jerárquicas que permite la noción de subalternidad; que reflexione de modo constante sobre el lugar del intelectual sin enmudecer; que, a contrapelo de expectativas y deseos populistas, pueda ver la reproducción de la dominación articulada en los implacables mecanismos de los medios de comunicación; y que, a contrapelo de expectativas y deseos legitimistas o reproductivistas, agudice el entrenamiento para leer allí mismo pliegues, fisuras, intersticios, tráficos" (Pág.302).

En Argentina la comunicad negra aún no cuenta con un movimiento social consolidado, se observa una serie de organizaciones en busca de maneras de unirse para constituir un gran frente y llegar a ser un movimiento como tal[14]. Es el caso de la agrupación La Familia estableciendo espacios de enunciación, para el candombe argentino [15] con un repertorio de acciones culturales populares para interpelar a dicha sociedad. 
Alabarces, Pablo. Añón, Valeria (2008) ¿Popular(es) o Subalterno(s). De la retórica la pregunta por el poder. En: Alabarces, Pablo. Rodríguez, María Graciela (2008) (Comp.), Resistencias y mediaciones: estudios sobre cultura popular. pp. 281-303, Buenos Aires, Paidós.

Andrews, George Reid (1989) Los afroargentinos de Buenos Aires 1800-1900, Buenos Aires, Ediciones de la Flor.

Bhabha, Homi (2007) El lugar de la cultura, Buenos Aires, Manantial.

Boas, Franz 1993 (1896) Las limitaciones del método comparativo en Antropología. En Renold J. M. Antropología Cultural. F. Boas, A. Kroeber, R. Lowie. Buenos Aires: CEAL.

Carvalho, José Jorge de (2004) "Las tradiciones musicales afroamericanas: de bienes comunitarios a fetiches transnacionales". En: Serie Antropología Nro. 320, Brasilia, 2002. Republicado en: Arocha, Jaime (org.), Utopía para los excluidos. El multiculturalismo en África y América Latina. Bogotá: Facultad de Ciencias Humanas, Universidad Nacional de Colombia.

Castells, Manuel (1974) Movimientos sociales urbanos, México, Siglo XXI editores.

Certeau, Michel de (1996) La invención de lo cotidiano. Artes de hacer. México, Universidad Iberoamericana.

Cirio, Norberto Pablo (2007) La música afroargentina a través de la documentación iconográfica, Bogotá D. C., 2007, Universidad Nacional de Colombia, núm. 13, pp. 127-155.

Frigerio, Alejandro (2000) Cultura negra en el Cono Sur: Representaciones en Conflicto. Buenos Aires, Ediciones de la Universidad Católica Argentina.

Gilroy, Paul (2008) Después del imperio, Barcelona, Tusquets.

Grimson, Alejandro. Semán, Pablo (2005) "Presentación: la cuestión "cultural". En: etnografías contemporáneas, (1): 11-20, Buenos Aires, Escuela de Humanidades /Unsam.

Grignon, Claude. Passeron, Jean-Claude (1991) Lo culto y lo popular. Miserabilismo y populismo en sociología y en literatura, Buenos Aires, Ediciones Nueva Visión.

Guha, Ränahit (2002) Las voces de la historia y otros estudios subalternos, Barcelona, Crítica.
Guha, Ränahit (1997) La prosa de contrainsurgencia, en: S. Rivera y R. Barragán (comp.), Debates post coloniales: una introducción a los estudios de subalternidad. Bolivia, Ed. Historias-SEPHIS-Aruwiri.

Hall, Stuart (1984) Notas sobre la reconstrucción "de lo popular". En: Samuel, Ralph (ed.), Historia popular y teoría socialista, Crítica, Barcelona.

Jaramillo Hincapié, Jorge Iván (2016) Las voces en los bordes de la historia. Presencias y ausencias de las/los afroargentinos en el Gran

Buenos Aires. España: Editorial Redactum.

Jaramillo Hincapié, Jorge Iván (2009) Praxis discursiva del Ejército Zapatista de Liberación Nacional de México. Un caso, las Seis Declaraciones de la Selva Lacandona. España: Editorial Académica Española.

Lamborghini, Eva. Frigerio, Alejandro (2010) Quebrando la invisibilidad: Una evaluación de los avances y las limitaciones del activismo negro en Argentina. Publicado en El Otro Derecho 41: 139-166. 2010. Revista del Instituto Latinoamericano de Servicios Legales Alternativos (ILSA). Número editado conjuntamente con el IDCARAN/CES, de la Universidad Nacional de Colombia. Bogotá, Colombia.

Martín-Barbero, Jesús (1993) De los medios a las mediaciones: Comunicación, cultura y hegemonía, México, Editorial Gustavo Gili.

Melucci, Alberto, (1994) "Asumir un compromiso: identidad y movilización en los movimientos sociales", en Zona Abierta $\mathrm{N}^{\circ}$ 69: Madrid.

Pérez Ledesma, Manuel (1994). "Cuando lleguen los días de la cólera (Movimientos Sociales, teoría e historia)". Revista Letra Internacional, número 34, Madrid.

Picotti, Dina (1998) la presencia africana en nuestra identidad, Buenos Aires, Ediciones Colihue.

Rodríguez, María Graciela (2008) La pisada, la huella y el pie. En: Alabarces, Pablo. Rodríguez, María Graciela (2008) (Comp.), Resistencias y mediaciones: estudios sobre cultura popular. pp. 281-303, Buenos Aires, Paidós.

Spivak, Gayatri (1985) “¿Puede el subalterno hablar?" (Traducción de José Amícola) en Revista Orbis Tertius, Año 6, Nº 6. Wolkmer, Antonio (2000) El humanismo en la tradición de la cultura jurídica latino-americana, en http://bibliotecavirtual.clacso.org.ar/ar/libros/ derecho/wolk1.rtf. 


\section{Otras fuentes:}

Archivo Histórico General de la Nación Argentina

Hemeroteca de la Biblioteca Nacional Argentina

Vídeos y charlas con la Asociación Civil Misibamba, su presidente Juan Suaqué, vicepresidenta María Elena Lamadrid y vocal Pablo Cirio.

Entrevistas con María Magdalena Lamadrid "Pocha" presidenta y fundadora de la Asociación Civil África Vive.

Entrevistas con Miriam Gomes (presidenta), Paulina Dias (ex-secretaria) y otros miembros de la Sociedad de Socorros Mutuos Unión Caboverdeana de Dock Sud, Buenos Aires.

http://bakongocandombeafroargentino.blogspot.co.

Coloquio que reunió a Elemar do Nascimento Cezimbra, Maristella Svampa, Raúl Prada Alcorezza, Luis Tapia y Raúl Zibechi en torno a la problemática "Movimientos sociales y nuevas prácticas políticas: logros y dificultades en la recreación del lazo social". Disponible en: http://lavaca.org/mu.shtml.

\section{Notas}

[1] Sobre este tema tanto en Uruguay como en Argentina existen hasta el día de hoy estudios realizados por académicos/as expertos en el tema: Alejandro Frigerio (1993, 2000), Pablo Cirio (2007), Eva Lamborghini (2010), etc.

[2] Aquí retomamos a Boas, para quien, de acuerdo con los principios del relativismo cultural, todas las culturas son iguales y comparables, en este punto Boas ve rasgos de heterogeneidad en las culturas: "La antropología moderna descubrió el hecho de que la sociedad humana crece y se desenvuelve de tal manera por toda parte, que sus formas, opiniones y acciones tienen muchos trazos fundamentales en común" (Boas 1993:25). Varios de los alumnos y teóricos cercanos a Boas retoman su trabajo sobre rasgos culturales y lo llevan a sus arenas de discusión, uno de ellos es Melville Herskovits quien en su libro El hombres y sus obras $(1952 / 1948)$ tiene todo un capítulo dedicado al tema de los rasgos, esto lo teoriza en las discusiones del momento como la antropología moderna descubrió el hecho de que la sociedad humana crece y se desenvuelve de tal manera por toda parte, que sus formas, opiniones y acciones tienen muchos trazos fundamentales en común" (Boas 1993:25). Varios de los alumnos y teóricos cercanos a Boas retoman su trabajo sobre rasgos culturales y lo llevan a sus arenas de discusión, uno de ellos es Melville Herskovits quien en su libro El hombres y sus obras $(1952 / 1948)$ tiene todo un capítulo dedicado al tema de los rasgos, esto lo teoriza en las discusiones del momento como la supervivencia de rasgos culturales africanos, y Sydney Mintz y Richard Price se suman a la apuesta teórica de Herskovitz en un completo diálogo con el autor, esto sin omitir sus puntos de vista haciéndole críticas: "...no niegan la posible existencia de continuidades en rasgos concretos, les parece más fructífero examinar la existencia de reglas, estructuras, principios o valores (frecuentemente inconscientes) que estructuran la producción de ciertas manifestaciones culturales afroamericanas y que serían equivalentes a los que operan en África (en Frigerio 2000: 31/32).

[3] Hago esta aseveración aun corriendo el riesgo de equivocarme pues según Pierre Bourdieu "Las ideas preconcebidas que desempeñan un papel fundamental en la conversación cotidiana tienen la virtud de que todo el mundo puede recibirlas y además instantáneamente por su banalidad son comunes al emisor y al receptor". Dice Bourdieu "Cuando se emite una idea preconcebida es como si eso ya se hubiera hecho. El problema está resuelto. La comunicación es instantánea porque, en un sentido, no existe. $O$ es sólo aparente. El intercambio de ideas preconcebidas es una comunicación con más contenido que el propio hecho de la comunicación". $\mathrm{Si}$ estas ideas preconcebidas de las que habla el autor son las que se dan en el cotidiano entre congéneres se puede entender desde ese lugar, pero si son las ideas 
preconcebidas emanadas de expertos o provenientes de la academia, en ese lugar es en el que nos posicionamos para señalar esta cuestión.

[4] Para una disertación completa sobre este tema en Homi Bhabha (2007) El lugar de la cultura, Manantial, Buenos Aires.

[5] "El grupo Bakongo está formado por afrodescendientes argentinos del tronco colonial de distintas generaciones. El repertorio que realiza incluye cantos y toques tradicionales de la comunidad afroargentina, así como también algunos de creación actual. Los cantos más antiguos se encuentran en lengua kikongo, en la mayoría de los casos, otros son en castellano combinados con palabras y oraciones en kikongo. Por su parte, los de creación reciente, están cantados enteramente en castellano. La música afroargentina que hoy muestra Bakongo al público en general, es el candombe en su expresión porteña y la rumba abierta, también de expresión porteña, y la zemba. En nuestros gestos y cantos, en nuestros tambores y cuerpos de historia desterrada viven nuestros ancestros...vivimos nosotros los afroargentinos y nuestra cultura, que se alza rebelde frente el olvido que sobre nuestros nombres pusieron..."

(http://bakongocandombeafroargentino. blogspot.co). Es una cita que nos aporta mucho material de análisis puesto que desde un comienzo se designan dentro del marco del Estado-nación, esa autoinclusividad no deja de estar dentro de la hegemonía de ese mismo Estado "blanqueador" que hasta el día de hoy no los reconoce como comunidad. Igualmente, manejan una interpelación que va desde lo nacional en su autodesignanción como "afroargentinos" y luego pasa a una escala local al expresarse como "porteños".

[6] Uno de los académicos más asertivo en este tema es George Reid Andrews (1989) quien es su libro Los afroargentinos de Buenos Aires 1800-1900, expone como tesis principal cuatro puntos que hasta el momento resuelven este interrogante: "Reclutados en grandes números en los ejércitos revolucionarios que combatieron a los españoles, los soldados afroargentinos lucharon luego sucesivamente contra los indios, los brasileños y los paraguayos [...] Esta explicación está íntimamente relacionada con la segunda, la del mestizaje, o mezcla racial. Enfrentadas a una escasez de hombres de su raza, y supuestamente deseosas de producir hijos de piel más clara con fines de movilidad social hacia arriba, las mujeres negras y mulatas se dirigieron a los hombres blancos como parejas. Este argumento combina la casi eliminación de los varones negros con el gran flujo de varones inmigrantes europeos posterior a 1850 , en una explicación lógica para la declinación de los afroargentinos. Un tercer argumento se centra en las bajas tasas de natalidad y las altas tasas de mortalidad que sufrieron los afroargentinos [...]. Una cuarta explicación, y bastante obvia, es la declinación del comercio de esclavos" (pp. 10/11). Una quinta sería la acomodación (en términos de Sherry Ortner) que puede verse cuando Reid Andrews refiere a la preferencia por autoclasificaciones emblanquecidas como "trigueño", "moreno", "mestizo", y más adelante a partir de la década del cincuenta"negro cabeza" "cabecita" o simplemente "cabeza" para designar lo "no blanco".

[7] Agradezco a los profesores Luís Ferreira y Alejandro Frigerio los comentarios que me llevaron a formular esta pregunta.

[8] Para una descripción completa, ver: Geler, 2008 y Cirio, 2009.

[9] El presente tema lo vengo trabajando desde el 2009 en el Congreso Nacional de Antropología en la Universidad de Buenos Aires, Facultad de Filosofía y Letras, donde se expuso un escueto texto con las primeras notas, al día de hoy ya se logró concretar y teorizar esa idea inicial.

[10] Inscribiéndonos en el paradigma de los Estudios Subalternos de la India.

[11] Cultura es siempre historia, agencia y poder, disputa y alteración. La vida social es una condición procesual, no una causa automática, de los modos de pensar y de actuar $\{. .$.$\} Hay sujetos, hay agencia, hay$ historia y, por lo tanto, la acción puede ir más allá de la propia base cultural, introduciendo una grieta, una fisura, siendo protagonista de cambios socioculturales (Grimson y Semán, 2005: 20).

[12] Para un estado de la cuestión ver Mellino, Miguel (2008) La crítica poscolonial. Descolonización, capitalismo y cosmopolitismo en los estudios poscoloniales, Buenos Aires, Paidós.

[13] Agradezco al profesor Luís Ferreira la concreción de esta idea. 
[14] Entendiendo movimiento social desde la óptica de tres autores que nos aportan desde el lugar de cada uno de ellos una amplia concepción del mismo. El teórico Raúl Prada Alcorezza quien manifiesta: "los movimientos sociales son un entramado de lenguajes y de gestos, que expresan tanto el mapa de síntomas de la crisis como la construcción de interpretaciones colectivas, discursos contra hegemónicos, procedimientos de trastrocamientos de las formas institucionales, recurrencias prácticas de la invención política popular. Los movimientos sociales abren horizontes de visibilidad, permiten introducir formas de conocimiento, elaborados colectivamente, hacen visible el engranaje opaco de las instituciones, muestran las fisuras de los aparatos de Estado, los desajustes de las instituciones de la sociedad civil, hacen patente las fuerzas que están en juego, las contradicciones micro sociales y territoriales, las contradicciones segmentarías, de género y generacionales, además de las de clase y de nacionalidades.

Los movimientos sociales hacen posible el conocimiento político (2007:1). Por otra parte, Paul Wilkinson (1971) define los movimientos sociales como un esfuerzo colectivo deliberado de promover cambios en alguna dirección y por cualquier medio, sin excluir la violencia, la ilegalidad, la revolución o la retirada a una comunidad utópica [...].

El compromiso del movimiento social con el cambio y la raison d'etre de su organización se basan en la volición consciente, el compromiso normativo con los objetivos o creencias del movimiento y la participación activa por parte de los seguidores o miembros del mismo (Wilkinson, 1971, en Pérez Ledesma, 2005: 62). Alberto Melucci (1994) aporta dos definiciones sobre movimientos sociales y acción colectiva que no están $\tan$ alejadas de los autores anteriores: la acción colectiva se ve representada como la respuesta reactiva a la crisis o desorden del sistema social.

La idea de movimiento social está contextualizada en las luchas directas con el desarrollo del sistema empresarial capitalista y se reconoce como el agente histórico que marcha hacia un destino de liberación o como la masa sugestionada y bajo control de unos pocos agitadores. Además de aportar estos dos términos, Melucci considera un término más englobador como son los fenómenos colectivos y los considera como resultado de múltiples procesos que favorecen o impiden la formación y el mantenimiento de las estructuras cognoscitivas y los sistemas de relaciones necesarios para la acción.

El fenómeno colectivo es, de hecho, producto de procesos sociales diferenciados, de orientaciones de acción, de elementos de estructura y motivación que pueden ser combinados de manera distinta (pp. 155/156).

[15] En todos los encuentros y presentaciones todos nuestros entrevistados/as advierten la necesidad de reivindicar el candombe argentino esto siempre en consonancia con el candombe uruguayo.

Para citar este artículo:

Jaramillo Hincapié, Jorge Iván (2019). EL CANDOMBE ARGENTINO COMO REPERTORIO DE ACCIÓN CULTURAL POPULAR. Revista Luciérnaga Comunicación. Vol. 11, Núm. 21. Pp 125 - 139.

DOI: https://doi.org/10.33571/revistaluciernaga.v11n21a6

OJS. http://revistas.elpoli.edu.co/index.php/luc/issue/archive

Link. https://www.politecnicojic.edu.co/index.php/revista-luciernaga 